\title{
En busca de la democracia spinoziana
}

\author{
In search of the Spinozian democracy
}

SALOMÉ ROJAS LILLO (iDa

\section{Resumen}

El objetivo de este escrito es exponer las características del Estado democrático como lo concibe Spinoza en su Tratado teológico político (1670), conciliando la libertad individual con la paz del Estado. Para esto, en primera instancia se contrastan los efectos de gobernar de forma autoritaria, liberal y democráticamente. Luego presento los fundamentos del Estado a partir del derecho natural individual y una ley universal humana para poder establecer los requisitos para que se conserve el Estado democrático: obediencia, fidelidad y libertad de expresión de parte de los súbditos, determinando los límites tanto de los individuos como de parte del Estado. Finalmente, se presenta la degeneración de la razón de Estado como la concibe Maquiavelo, dejando abierta la reflexión para lo que sucede en el ámbito de la política actual.

Palabras claves: Spinoza. Estado. Democracia. Suprema potestad. Súbditos.

\begin{abstract}
The purpose of this investigation is to show the characteristics of the democratic State as thought by Spinoza in his "Political theological treaty" (1670), conciliating the individual freedom with the State Peace. To do so, in the first place the effects of governing in an authoritarian, liberal and democratic way will be contrasted. In the second place, I introduce the fundaments of the State from the natural individual rights and a universal human law to establish the conditions that keep the democratic State such as obedience, loyalty, and freedom of speech. In this way, both the limits of the individual and the State ones are delimited. Finally, Machiavelli's theory of State is introduced in order to promote discussion and thought about what is currently happening in politics.
\end{abstract}

Keywords: Spinoza. State. Democracy. Supreme power. Subjects.

a Universidad de Valparaíso, Valparaíso, Chile. Mestre en Filosofía, e-mail: emolas_x@hotmail.com 


\section{Introducción}

El Tratado teológico político fue publicado en 1670 de forma anónima y con pie de imprenta falso, datos reveladores por sí mismos de la necesidad de emprender una defensa de la libertad de expresión que se enmarca dentro de la filosofía política. Efectivamente, el tema central del Tratado es, según declara explícitamente su autor, intentar determinar hasta dónde puede extenderse, en un Estado bien organizado, la libertad de pensar y decir lo que uno piensa. Las reflexiones de Spinoza respecto de esta materia conservan plena validez y deberían aplicarse a cualquier tipo de régimen, no tanto por razones morales, sino porque resulta políticamente eficiente. (MIRANDA, 1988, p. 235). ${ }^{1}$ A continuación se expone una situación que arroja luz sobre la manera efectiva de gobernar respetando los derechos individuales, es decir, de forma democrática, entendiendo la connotación real de este concepto.

A través de esta serie de textos que van desde la mitad del siglo v hasta la mitad del iv a. C. podemos seguir con precisión los matices de la coloración del término «democracia», que conservando siempre su fuerte contenido normativo, centrado en la noción de «igualdad ante la ley» y de «iguales derechos para todos los ciudadanos», va desplazando el aura religiosa que la rodea al comienzo por un compromiso intelectual y moral de tipo personal, que liga a cada ciudadano con un sistema de solidaridades institucionales. (GUARIGLIA, 2010, p. 163). ${ }^{2}$

En 1939 el sicólogo alemán Kurt Lewin ${ }^{3}$ lleva a cabo un experimento sobre liderazgo que viene a corroborar lo que Spinoza había pensado tres siglos atrás. El experimento consistía en lo siguiente: se formaron tres grupos de niños de aproximadamente diez años que participarían en un taller de manualidades. Cada grupo seguiría las instrucciones de un líder a través de un monitor para completar varios

\footnotetext{
${ }^{1}$ Carlos Miranda es Licenciado en Filosofía, Universidad de Chile, Master of Arts en Ciencia Política, Georgetown University. Profesor de la Facultad de Ciencias Económicas y Administrativas, Universidad de Chile y del Instituto de Ciencias Política de la P.U.C. A lo largo de este escrito se hará referencia a su Estudio: Libertad de expresión: el argumento de Spinoza de forma implícita en relación con el Tratado teológico político.

${ }^{2}$ Más sobre el concepto mismo de democracia en: Democracia: origen, concepto y evolución según Aristóteles de Osvaldo Guariglia (1938-2016): filósofo argentino conocido por sus contribuciones en ética y teoría política contemporánea.

${ }^{3}$ Kurt Lewin (1890-1947) fue un psicólogo alemán nacionalizado estadounidense. Realizó investigaciones sobre la psicología de los grupos y las relaciones interpersonales. Se interesó por el comportamiento de las personas que seguían a los dictadores, llegando a ser manipulados hasta el punto de perder su individualidad.
} 
objetivos; en un grupo el estilo del líder era autocrático, en otro era liberal ${ }^{4}$ y en el otro democrático. A los niños que fueron liderados de forma autocrática se les impuso lo que tenían que hacer, sin tomar en cuenta sus opiniones y se les castigaba si no cumplían; a los niños que fueron liderados de forma liberal se les permitía que hicieran lo que quisieran, les proporcionaban el material, la información y la ayuda si la pedían; y a los niños que fueron liderados democráticamente se les guiaba tomando en cuenta sus opiniones, haciendo todo por común decisión de todos. Spinoza tiene clara esta función del Estado democrático.

Los resultados del experimento fueron los siguientes: los niños gobernados autocráticamente eran absolutamente sumisos ante su líder, trabajaban y se esforzaban solo cuando el líder los observaba, pero cuando se alejaba la motivación decaía completamente, perdieron la creatividad y el compañerismo, siendo violentos entre ellos mismos. Los niños que fueron gobernados por el líder liberal reflejaban desorganización, no trabajaban, hacían el mínimo de esfuerzo, no cumplían ninguna de sus metas. Finalmente, los niños gobernados por el líder democrático mostraron rasgos muy positivos, trabajaban en equipo, cumplían sus metas, trabajando continuamente para lograrlo. (FOLADORI, 2002, p. 4).

Esta clase de experimento hoy en día es considerado antiético por involucrar a niños, pero nos muestra una visión clara para saber cuál es el estilo de liderazgo más efectivo a la hora de dirigir un grupo en un trabajo, según los resultados de este experimento, sin duda, el mejor estilo de liderazgo es el democrático. Si el líder actúa de forma autoritaria o si les otorga demasiada libertad es probable que no se cumplan los objetivos y no se viva en la paz y la concordia.

\section{Argumento de Spinoza a favor del Estado democrático}

En el capítulo XVI del Tratado teológico politico Spinoza trata sobre los fundamentos del Estado. En primer lugar, se refiere al derecho natural de cada individuo, sin mencionar al Estado por el momento. Por derecho de la naturaleza entiende las reglas de la

\footnotetext{
${ }^{4}$ En el artículo que se parafrasea, este estilo de liderazgo es llamado "laissez-faire": palabra francesa que significa "dejar hacer".
} 
naturaleza, según las cuales cada ser está determinado naturalmente a existir y a obrar de una forma precisa y no puede obrar de otro modo. Cada individuo tiene el máximo derecho a todo lo que puede, esto es, a existir y actuar tal como está determinado por naturaleza; conforme con la ley suprema de la naturaleza que señala que cada cosa debe esforzarse, cuanto puede, en perseverar en su estado por sí sola, sin relación alguna a otra ${ }^{5}$. Esta ley rige tanto para los hombres como para los demás seres de la naturaleza. Spinoza ejemplifica con los peses, cuyo derecho natural los determina a nadar y a los grandes a comerse a los chicos.

Por lo tanto, según Spinoza, el derecho de la naturaleza no se dispone por las leyes de la razón humana, sino por los impulsos del apetito que arrastran a cada uno por su lado, generando el odio, el engaño o cualquier otra inclinación del apetito. Ahora bien, todas las personas desean vivir, en cuanto puedan, con seguridad y sin miedo. Para esto, los hombres tuvieron que unir necesariamente sus esfuerzos, concediendo el derecho que cada uno tenía por naturaleza a todos colectivamente, de manera que ya no estuvieran determinados según el apetito de cada uno, sino según el poder y el deseo de todos, esto es, someter el apetito a los dictámenes de la razón, frenando el impulso que aconseje perjudicar al otro y defendiendo el derecho ajeno como el propio.

Otro aspecto a considerar para la formación del Estado es la ley universal de la naturaleza humana que establece que de dos bienes cada uno elegirá el que le parece mayor, y de dos males, el que le parece menor. De esta ley se sigue que las personas son fieles a sus promesas por la esperanza de un bien mayor o por el miedo a un mal mayor. Así, pues, una sociedad se forma en la medida en que cada uno le trasfiere parte de su poder y de esta forma cederá también parte de su derecho, ya sea por propia iniciativa (la razón lo aconseja) o por miedo a algún suplicio (la necesidad les obliga). El derecho de dicha sociedad se llama democracia que se define como la asociación general de los hombres, que posee el supremo derecho a todo lo que puede, por lo tanto, todos deben obedecerla en todo, es decir, cumplir absolutamente todas las órdenes de la potestad suprema, si no, serían enemigos del Estado y obrarían contra la razón que nos manda a cumplir dichas órdenes, ya que de dos males se elige el menor. Pero a las supremas

\footnotetext{
${ }^{5}$ Esta ley suprema coincide con el conato (del latín "conatus": esfuerzo, empeño, impulso, inclinación). El término es utilizado para referirse a una inclinación innata de la materia o de la mente por seguir existiendo y mejorándose.
} 
potestades les interesa velar por el bien común y dirigirlo todo conforme al dictamen de la razón, manteniendo la paz y la concordia y de esta forma poder conservar el mando, pues los gobiernos violentos no se mantienen en el tiempo. ${ }^{6}$ (SPINOZA, 2014, p. 406-416).

\section{Obediencia de parte de los súbditos a la suprema potestad}

En consecuencia, Spinoza plantea que la primera condición para la conservación del Estado es la completa obediencia de parte de los súbditos a todas las órdenes que provienen del poder supremo; esto pareciera no dejar espacio para la libertad de los individuos dentro del Estado, convirtiendo a los súbditos en esclavos. Para comprenderlo debemos entender que la libertad spinoziana no se define por la simple espontaneidad, es decir, porque cada uno viva a su antojo llevado por sus apetitos, siendo incapaz de ver ni hacer nada útil; esto sería ser esclavo al máximo. Es el fin de la acción lo que hace que uno sea libre o esclavo; si el fin de la acción no es útil al agente, sino solo para el que manda, entonces el agente es esclavo e inútil para sí; en cambio, en el Estado democrático el fin es la suprema ley que es la salvación del pueblo, por eso, quien obedece en todo a la suprema potestad no debe ser considerado como un esclavo inútil para sí mismo, sino como súbdito con máxima libertad, es decir, viviendo sinceramente según la guía de la razón. La razón nos revela que por amor a nosotros mismos (impulso natural de nuestro instinto primario por sobrevivir) debemos procurar llevar una vida feliz y segura; propósito inalcanzable en el estado de naturaleza, que es un estado de guerra de todos contra todos; por tanto, por ese amor a nosotros mismos, los hombres debemos llegar a ese acuerdo.

Como caso análogo, Spinoza nos dice que los hijos tienen que obedecer en todo a sus padres y no por eso son esclavos, ya que los preceptos paternos buscan la utilidad de los hijos para sí mismos. La diferencia entre los hijos y los súbditos es que los primeros al obedecer a sus padres son útiles para sí mismos, en cambio, los súbditos al obedecer a la autoridad suprema son útil tanto para sí mismo como para la comunidad. (SPINOZA, 2014, p. 416-418).

\footnotetext{
${ }^{6}$ Para hacer esta afirmación Spinoza se apoya en Séneca, contrario al pensamiento de Maquiavelo.
} 
Una vez que Spinoza ya nos ha mostrado los fundamentos del Estado democrático define el derecho civil privado como: “(...) la libertad de cada cual a conservarse en su estado, tal como es determinada por los edictos de la potestad suprema y defendida por su sola autoridad.” (SPINOZA, 2014, p. 419). Puesto que, una vez que cada uno transfirió su derecho de vivir a su antojo al Estado, está obligado a vivir según la razón de éste y a defenderse con su sola ayuda, pero eso no significa que debe renunciar a pensar por sí mismo: "El individuo, en sociedad y a cambio de la seguridad que la misma le otorga, renuncia al derecho de actuar según su ley particular, pero no al derecho de razonar y juzgar.” (MARTÍMEZ, 2007, p. 230-231).

\title{
Fidelidad de los súbditos
}

En el capítulo XVII del Tratado teológico político Spinoza somete a revisión la teoría de la absoluta obediencia de parte de los súbditos y también el derecho absoluto de parte del soberano. Este absolutismo es imposible realizarlo en la práctica, en efecto, se dejaría de ser hombre si a los súbditos se les privara totalmente del derecho natural para beneficiar a otro, el soberano no puede disponer de todo el poder a su antojo, pues existen órdenes que sería imposible que los súbditos acataran sin violentar la naturaleza humana, tales como amar a sus enemigos, odiar a alguien que le haya hecho un favor; y otras cosas similares. (SPINOZA, 2014, p. 429).

\begin{abstract}
En efecto, el contrato social spinoziano impone límites a los derechos tanto del soberano como de los individuos. Estos, al ingresar a la sociedad civil, renuncian a su derecho natural a todas las cosas, pero no ceden su derecho a buscar lo que consideran útil para sí mismos. (MIRANDA, 1988, p.247).
\end{abstract}

Por otra parte, todo gobernante, tiene siempre que temer tantos peligros de parte de los enemigos extranjeros como de sus propios súbditos ${ }^{7}$. La única manera que tiene para evitar estas amenazas potenciales, es logrando captar la fidelidad de ellos. La fidelidad hacia el Estado se define por las obras, Spinoza plantea que se debe conceder a cada uno

\footnotetext{
${ }^{7}$ Spinoza ejemplifica con la República Romana, invicta frente a sus enemigos y vencida y oprimida por sus ciudadanos. Véase en el Tratado teológico político, p. 434-435.
} 
la libertad de filosofar, ${ }^{8}$ y lo justifica de la siguiente manera: primero supone que la libertad es oprimida, impidiendo que los hombres osen decir ninguna palabra diferente de lo que piensan las supremas potestades sin su permiso; la consecuencia sería que los hombres pensarían frecuentemente algo distinto de lo que dicen, de este modo se fomenta la adulación y la perfidia que son la fuente del engaño y de la corrupción. Además, como por naturaleza humana cuanto más se intenta quitar la libertad de hablar, más se empeñan los hombres por hacerlo, se sigue que las leyes que se dictan sobre las opiniones, ya no se dirigen contra los malintencionados, sino más bien contra los hombres de bien (SPINOZA, 2014, p. 508-510). Por tanto, semejantes leyes serían de gran peligro para el propio Estado, de esta manera Spinoza concluye que:

[...] para que se aprecie la fidelidad y no la adulación y para que las supremas potestades mantengan mejor el poder, sin que tengan que ceder a los sediciosos, es necesario conceder a los hombres la libertad de juicio y gobernarlos de tal suerte que, aunque piensen abiertamente cosas distintas y opuestas, vivan en paz. No cabe duda que esta forma de gobernar es la mejor y la que trae menos inconvenientes, ya que está más acorde con la naturaleza humana. (SPINOZA, 2014, p. 511).

De los fundamentos del Estado democrático, explicados anteriormente, se sigue que su fin último no es dominar a los hombres por el miedo, sino, por el contrario, librarlos del miedo para que vivan con la mayor seguridad que se pueda; esto es, para que conserven al máximo su derecho natural de existir y de obrar sin dañarse a sí mismo ni a los otros.

\section{Libertad de pensamiento de los súbditos}

En el capítulo XX, advierte Spinoza, que es imposible que la propia alma ${ }^{9}$ se someta a otro: “(...) nadie puede transferir a otro su derecho natural o su facultad de razonar libremente y de opinar sobre cualquier cosa, ni ser forzado a hacerlo." (SPINOZA, 2014, p. 500). En consecuencia, considera violento un Estado que impere sobre las almas, es decir, que, si la suprema potestad prescribe a cada uno la opinión que

\footnotetext{
${ }^{8}$ Spinoza menciona sin entrar en detalles que esta libertad de filosofar es primordial para promover las ciencias y el arte.

${ }^{9}$ Alma del latín animus que significa espíritu. También utiliza la palabra alma como sinónimo de mens que significa mente, pensamiento.
} 
debe aceptar como verdadera y rechazar como falsa estaría cometiendo injuria contra los súbditos, usurpando sus derechos. En cambio, considera moderado al Estado que concede la libertad de opinar y pensar lo que quiera, ya que, por el supremo derecho de la naturaleza, cada uno es dueño de sus pensamientos. No obstante, no podemos negar que también la suprema potestad puede ser agredida con palabras. Por tanto, si bien es imposible quitar totalmente esta libertad a los súbditos, sería pernicioso concedérsela sin límites (SPINOZA, 2014, p. 500-503). Por eso, Spinoza se propone determinar los límites de la libertad tanto de los súbditos como del Estado.

Para vivir en paz, dado que el juicio de los hombres es muy variado, cada individuo renunció al derecho de actuar por propia decisión, acatando los decretos de las supremas potestades; pero sí puede pensar, juzgar e incluso hablar con la condición de que al hablar o enseñar defienda algo con la sola razón y no con engaños, iras, odios, ni con la autoridad de sus decisiones para introducir algo nuevo en el Estado. Spinoza ejemplifica de la siguiente manera: alguien estima que hay que abrogar una ley porque prueba que contradice a la sana razón, esta opinión la somete al juicio de la suprema potestad (la única que puede dictar y abrogar leyes) y entre tanto, no hace nada en contra de lo que prescribe dicha ley; ese hombre sería estimado honorable ante el Estado; de esta forma puede y debe proceder un súbdito sin menoscabo de la justicia y la piedad. Si, por el contrario, acusa de inequidad al magistrado, obrando de tal manera de generar odio en la gente hacia la suprema potestad, o intenta abrogar la ley en contra de la voluntad del magistrado, será un hombre perturbador declarado rebelde. Por tanto, las opiniones que son sediciosas para el Estado son aquellas que implican la ruptura del pacto por el que cada uno renunció a su derecho de obrar según su propio criterio, es decir, las opiniones que llevan consigo el hecho que contradice al pacto como la venganza, la ira, etc. (SPINOZA, 2014, p. 504-505).

De esta forma Spinoza ha justificado que la libertad de pensamiento y opinión no solo puede ser concedida sin perjudicar la paz del Estado, sino que debe ser concedida para que pueda ser conservada. La suma piedad es aquella que tiene por objetivo la paz y la tranquilidad del Estado. En suma, nuestro filósofo concilia la libertad individual con la obediencia de parte de los súbditos hacia la suprema potestad, manteniendo la piedad del Estado. 


\section{Perversión de la razón de Estado desde Maquiavelo hasta nuestros días}

La estabilidad de la república se confía, en ciertas posiciones republicanas, a la búsqueda de instituciones justas, y en otras, a la necesidad de la virtud individual como base de la virtud colectiva. Espinosa, (...), se acercará más a las primeras y rechazará la exigencia de unos ciudadanos inicialmente virtuosos como un idealismo irreal y utópico (MARTÍNEZ, 2007, p. 226).

En su origen la política entendida como república y el arte de Estado eran nociones antitéticas. La política tiene por objetivo el bien común suponiendo que el gobernante se guía por la razón, fomentando la igualdad y la justicia, en cambio, el arte de Estado busca el beneficio del príncipe y de los que lo rodean, fomentando sus propios intereses y su superioridad con respecto a los ciudadanos que pone a su servicio. La noción de arte de Estado va evolucionando hasta convertirse en la idea mucho más popular de razón de Estado. (MARTÍNEZ, 2007, p. 287-289). Botero ${ }^{10}$ definía la razón de Estado como: "Un conocimiento perfecto de los medios a través de los cuales los Estados se refuerzan, duran y crecen" (BOTERO, 1590). La razón de Estado vendría a ser un saber aplicado, un conjunto de medios (razón instrumental), cuyo objetivo es la conservación y el crecimiento del Estado, manteniendo la paz y el orden sin reconocer límites morales o religiosos, surgiendo la instauración de la política como un ámbito autónomo. (MARTINEZ, 2007, p. 291).

La razón de Estado suponía actuar según la justicia y esta concepción se mantendrá en la razón de Estado cristiana. La única posibilidad de trasgredir la ley de forma justificada era el estado de necesidad; la necesidad permitía utilizar medidas excepcionales, pero estas actuaciones extraordinarias no se ajustaban a la razón de Estado. Maquiavelo $^{11}$, considera lo extraordinario del estado de necesidad como la situación habitual en política, lo que hace que las técnicas de actuación del tirano se extiendan al poder legítimo. En su obra El príncipe (1513) pervierte la tradición medieval de los "espejos de príncipes" que funda el buen gobierno en la virtud personal del príncipe que

\footnotetext{
10 Giovanni Botero (1533-1617) fue un estadista y economista en contra del pensamiento de Maquiavelo.

11 Nicolás Maquiavelo (1469 - 1527) fue diplomático, filósofo político y escritor italiano, considerado padre de la Ciencia Política moderna.
} 
es un ejemplo para los súbditos. La virtud ya no se entiende como virtud moral, sino como acción eficaz. El príncipe deja de estar sujeto al imperativo de la perfección moral, pasando al imperativo de la conservación del poder y del Estado, para lo cual es preciso un exacto conocimiento de las propias fuerzas y de las fuerzas ajenas; de esta forma se pasa de la ética a la "estadística", legitimando por la razón del Estado que el fin justifica los medios y la existencia de una doble moral: una propia del Estado y del político en oposición a la moral de la Sociedad, del ciudadano común, fundada en la tradición y en la religión. La historia política moderna y contemporánea ha estado guiada por la intención de suprimir esa contradicción. "El verdadero problema de la razón de Estado es la doble moral, congruente con cualquier tipo de pensamiento de izquierdas o de derechas, conservador o reaccionario.” (NEGRO PAVÓN, 1989, p. 6). ${ }^{12}$

\section{Conclusiones}

El argumento spinoziano a favor del Estado democrático justifica que el poder soberano solo tiene aplicación en el ámbito de las acciones y que es necesario permitir la libertad de pensamiento, ya que de lo contrario se generarían consecuencias negativas a nivel moral y político, destruyendo la concordia del Estado. Su apuesta va dirigida hacia la búsqueda del Estado justo que se encuentra pervertido tal como señala Maquiavelo, cuya obra es conocida directamente y valorada por Spinoza.

Ciertamente no ha sido la filosofía política de Spinoza la que ha animado a la inmensa mayoría de los regímenes políticos de todos los tiempos. Spinoza no solo conocía esta realidad, sino que por propia experiencia había padecido los rigores de la intolerancia sobre la libertad de pensamiento, contra lo cual está precisamente dirigido el Tratado teológico político. En esta obra él no propone la libertad de expresión como un objetivo ideal, sino que afirma que es la verdadera finalidad de todo gobierno, ya que para velar por la seguridad de la sociedad se debe conceder dicha libertad, restringiendo más las acciones provenientes del estado de naturaleza de los hombres.

\footnotetext{
${ }^{12}$ Dalmacio Negro Pavón (1931) es catedrático español y miembro de la Real Academia de Ciencias, Morales y Políticas.
} 


\section{Referencias}

FOLADORI, H. C. La concepción del liderazgo en Kurt Lewin. Artículos, 2002.

GUARIGLIA, O. Democracia: origen, concepto y evolución según Aristóteles. Doxa, Cuadernos de Filosofía del Derecho, n. 33, p. 157-190, 2010.

MARTÍNEZ, F. J. Autoconstitución y libertad - Ontología y política en Espinosa. Barcelona: Anthropos Editorial, 2007.

MIRANDA, C. Libertad de expresión: el argumento de Spinoza. Revista Estudios Públicos, n. 29, p. 232-257, 1988.

NEGRO PAVÓN, D. La razón de Estado. Cuenta y razón, n. 51-53, 15-22 1989.

SPINOZA, B. Tratado Teológico-Político. Madrid: Alianza Editorial, 2014.

RECIBIDO: $25 / 05 / 2020$

APROBADO: $14 / 06 / 2020$

RECEIVED: 05/25/2020

APPROVED: 06/14/2020 